\title{
AVALIAÇÃO DA QUALIDADE DOS REGISTROS DE ENFERMAGEM NOS PRONTUÁRIOS DA CLÍNICA CIRÚRGICA DO HOSPITAL MUNICIPAL DE BRUMADO/BA POR MEIO DA AUDITORIA
}

LIRA, Manuella Amorim de Mello ${ }^{1}$

LIRA, Manuella Amorim de Mello. Avaliação da Qualidade dos Registros de Enfermagem nos Prontuários da Clínica Cirúrgica do Hospital Municipal de Brumado/BA por Meio da Auditoria. Revista Científica Multidisciplinar Núcleo do Conhecimento. Edição 9. Ano 02, Vol. 03. pp 24-36, Dezembro de 2017. ISSN:24480959

\section{RESUMO}

O objetivo desse trabalho é avaliar, por meio de auditoria, a qualidade dos registros de enfermagem nos prontuários de pacientes atendidos na Clínica Cirúrgica do município de Brumado/BA. Este estudo é descritivo e retrospectivo e a metodologia de pesquisa é documental em campo; foram avaliados 100 prontuários no mês de março de 2015, analisados os itens: admissão de enfermagem, prescrição de enfermagem, evolução de enfermagem, assinatura, carimbo; letra legível; diagnóstico de enfermagem; checagem de enfermagem; checagem da prescrição médica, folha de centro cirúrgico, folha de gasto, anotação de alta hospitalar ou óbito. Essa pesquisa possibilitou apontar vários erros que foram analisados, como letras ilegíveis, ausência da prescrição de enfermagem, admissões incompletas, em geral a baixa qualidade do serviço de enfermagem, propiciando proposta de nova meta para melhoria do registro dessa assistência.

Palavras-Chave: Qualidade, Registros, Auditoria, Enfermagem.

\footnotetext{
${ }^{1}$ Especialista em Enfermagem do trabalho, Enfermeira na Clínica de Hemodiálise, INEB
} 


\section{INTRODUÇÃO}

A auditoria, na atualidade, vem crescendo no mercado competitivo no qual apresenta uma ferramenta relevante para aferição da qualidade e custos das agremiações de saúde. Segundo, ANDRADE, 2016, auditoria se faz de uma análise sistemática e formal através de pessoas que não estão envolvidas em suas atividades a fim de determinar se a ação está de acordo com os objetivos.

Sendo ainda um campo de desafio para os enfermeiros auditores por ser uma atuação versátil pouco explorada onde existe uma relevante evolução nessa área. (SILVIA, et al., 2009) No desenvolvimento da auditoria de prontuários encontramos como foco a verificação dos serviços prestados pela equipe de enfermagem, identificando a falha na assistência, procurando melhorar a qualidade e satisfação do paciente na unidade.

A equipe de enfermagem tem um papel de grande importância nos registros em prontuário de sua execução com o paciente, sendo a equipe que mais permanece junto ao paciente e família, nesse contexto é fundamental a pesquisa para desenvolver e promover uma discussão teórica sobre a importância das anotações, clareza, veracidade e ética. (SILVA, 2009).

Com isso as anotações de enfermagem têm um grande valor como fonte de averiguação. As evoluções mal construídas, letras ilegíveis, no qual irá dificultar o entendimento da mesma, pode gerar múltiplos sentidos, sendo um documento relevante que relata a vida de um paciente dentro de uma unidade hospitalar. (SETZ, 2009). Com as considerações citadas sobre a importância das anotações de enfermagem os prontuários não contêm informações necessárias para um processo judicial, existe um descaso quanto ao tipo de formalização escrita e a falta de anotações no prontuário do paciente que muitas vezes dificulta o exercício da proteção dos direitos dos profissionais de enfermagem judicialmente ou administrativamente. (SETZ, 2009).

Desse modo "Qual a importância da avaliação da qualidade dos registros de enfermagem nos prontuários da clínica cirúrgica do hospital municipal de brumado/BA 
por meio da auditoria?" Diante do relatado é relevante um prontuário bem feito para que seja investigada a forma na qual foi tratado o paciente diante uma internação hospitalar para que tenha tido os cuidados necessários, identificando as falhas e que os profissionais podem ter uma reflexão do seu trabalho.

O objetivo desse estudo foi avaliar por meio da auditoria a qualidade dos registros de enfermagem nos prontuários da clínica cirúrgica do Hospital Municipal de Brumado/BA.

Tendo como objetivos específicos:

- Melhorar o serviço prestado ao cliente;

- Atender as expectativas do paciente e família;

- Aperfeiçoar os recursos disponíveis para o paciente;

- Reduzir a perda financeira medindo glosas;

- Subsidiar o trabalho de educação continuada das equipes de trabalho;

- Identificar as áreas (unidades) deficientes do serviço de enfermagem;

- Identificar áreas de deficiência em relação à assistência de enfermagem prestada;

- Fornecer dados para melhoria dos programas de enfermagem;

- Fornecer dados para melhoria da qualidade do cuidado de enfermagem;

- Obter dados para programas de extensão e atualização do pessoal de enfermagem.

\section{DESENVOLVIMENTO}

\section{AUDITORIA}

\section{CONHECENDO A AUDITORIA}

Segundo CLEMAN et al. (1998), a auditoria nasceu com o objetivo de controle e análise contábil, registrar anotações financeiras, ouvir reclamações dando uma sequência para uma melhoria da qualidade. Na Inglaterra, durante a Revolução 
Industrial, século XVIII, os negócios se expandiram e a auditoria acompanhava o que era produzido e chegava ao destino final, identificando a necessidade de padronizar os processos de produção da forma correta.

Para MAUTZ (1985), auditoria em saúde teve inicio nos EUA, em 1918, com Dr. George Ward, com foco na avaliação da qualidade assistencial, analisando o registro nos prontuários de pacientes, visando atenção e qualidade do atendimento. Com o passar do tempo e o aprimoramento da eficiência da auditoria adquiriu importância a partir da década de 1980.

Para CLEMAN et al. (1998), em 1990, a Lei 8.080 estabeleceu a necessidade de criação do Sistema Nacional de Auditoria - SNA, em 1993 deu-se a responsabilidade ao SNA do acompanhamento, da fiscalização, do controle, da avaliação técnicocientífica, contábil, financeira e patrimonial das ações e serviços de saúde.

A auditoria tem como finalidade:

Aferir a preservação dos padrões estabelecidos e proceder ao levantamento de dados que permitam ao SNA conhecer a qualidade, a quantidade, os custos e os gastos da atenção à saúde; avaliar objetivamente os elementos componentes dos processos da instituição, serviço ou sistema auditado, objetivando a melhoria dos procedimentos, através da detecção de desvios dos padrões estabelecidos; avaliar a qualidade, a propriedade e a efetividade dos serviços de saúde prestados à população, visando a melhoria progressiva da assistência à saúde; produzir informações para subsidiar o planejamento das ações que contribuam para o aperfeiçoamento do SUS e para a satisfação do usuário. (PRADO; 1998, p. 07)

Existem três tipos de auditoria: a prospectiva, a concorrente e a retrospectiva. A auditoria prospectiva é realizada antes da ocorrência do evento assistencial, ou seja, antes do paciente entrar na unidade hospitalar, é de caráter preventivo, sendo uma das fases mais importante da auditoria na prevenção de glosas. A auditoria concorrente é a auditoria feita enquanto o paciente está hospitalizado ou em 
atendimento ambulatorial. A auditoria retrospectiva é realizada após a alta do paciente, por meio de análise do prontuário, do qual trata o presente estudo.

\section{AUDITORIA EM ENFERMAGEM E SUA QUALIDADE}

Os registros de enfermagem é relevante meio de comunicação não verbal entre os profissionais, tendo uma necessidade de que sejam realizadas dentro dos princípios morais. (MATSUDA et al., 2006). Estes registros são imprescindíveis para a valorização da classe, importantes meios jurídicos e excelente material didático para novas pesquisas e educação continuada, promovendo a qualidade na assistência, satisfação do usuário e ainda evita processos judiciais e perdas financeiras. (SILVA, 2009)

Para Zanon (2001), no Brasil, "a qualidade da assistência de muitos hospitais ainda é pressuposta pelo grau de capacitação científica e tecnológica dos agentes", sendo assim tendo uma grande necessidade de qualificação dos profissionais da área de saúde.

Segundo KURCGANT (1976), há uma relação positiva entre os registros e a qualidade do cuidado, podendo-se avaliar os cuidados de enfermagem por meio de registros, os quais refletem a qualidade da assistência. Também definida como análise de anotações de enfermagem com o propósito que se pretende alcançar, verificar e favorecer a assistência e como um método utilizado na avaliação da qualidade do cuidado por meio dos registros após a alta do paciente. (SETZ, 2009)

É um sistema de revisão e controle, para informar a administração sobre a eficiência e eficácia dos programas em desenvolvimento, sua função não indica somente falhas, apontando também sugestões e soluções assumindo um caráter educacional.

Espera-se de uma auditoria de enfermagem que os profissionais de saúde tenham um compromisso e responsabilidade com os prontuários, realizando uma melhoria do serviço prestado e reduzindo a perda financeira, uma vez que uma das dificuldades da equipe é registrar suas ações. Para MAUTZ (1985), a auditoria divide-se em duas 
vertentes: qualidade - auditoria de cuidados que se dirija ao usuário, paciente na qualidade da assistência prestada, satisfação do cliente e satisfação da unidade e, custos - auditoria de custos obtendo a melhor assistência com o melhor custo possível. Ainda segundo MAUTZ (1985), a auditoria de enfermagem possui os seus princípios: justiça - equidade, dar a quem precisa mais; beneficência melhorar as condições do paciente e não maleficência não causar danos, minimizar os prejuízos. Esses princípios estão ligados à bioética que se interessa pelos princípios morais diante do ser vivo e tem como essência a importância da valorização e respeito à pessoa humana que todos nós devemos ter.

\section{PRONTUÁRIO MÉDICO E SUA IMPORTÂNCIA}

Segundo o Conselho Regional de Medicina de São Paulo, "o prontuário médico ou prontuário do paciente é um conjunto de documentos protocolados, destinados ao registro de todas as informações referentes aos cuidados médicos prestados ao paciente." (Conselho Regional de Medicina de São Paulo, 2001).Toda a equipe que fizer uso do mesmo terá obrigação de assinar e carimbar, ou, assinar, escrever seu nome legível e seu conselho.

No prontuário médico do paciente deve conter: ficha de registro de atendimento ambulatorial ou de urgência; evolução médica; prescrição médica; evolução de enfermagem, fonoaudióloga, nutricionista, assistente social, fisioterapeuta e de outros profissionais assistentes; prescrição de enfermagem e de outros profissionais assistentes; exames complementares; descrição cirúrgica, boletim anestésico; folha de gasto; resumo de alta.

\section{AS ANOTAÇÕES DE ENFERMAGEM E SUA RELEVÂNCIA}

Segundo o Conselho Federal de Enfermagem, "a enfermagem na sua essência é uma profissão comprometida com a família, coletividade, qualidade de vida da pessoa e principalmente com a saúde." (Conselho Federal de Enfermagem, 2012) 
Segundo SANTOS et al. (2003), a equipe multiprofissional da enfermagem é responsável por metade das referências contidas no prontuário, sendo que a mesma produz diariamente informações que estão ligadas ao cuidado do paciente.

Nesse sentido não basta só a quantidade, sendo necessário a qualidade dos registros. O mesmo autor na sua pesquisa relata que as anotações são inconscientes, ilegíveis e subjetivas, não havendo uma definição metodológica estruturada. Para ITO et al. (2005), o cuidado na hora de registrar no prontuário do paciente é essencial e deverá especificar os itens observados e avaliados, com clareza e objetividade.

As admissões e evoluções de enfermagem devem ser registradas com seriedade todos os tipos de ocorrências realizadas com o cliente durante sua estadia numa unidade hospitalar ou em outras instituições, sendo elas SSVV, punções, troca de fralda, queixas, avaliações médicas, soroterapia, oxigenoterapia dentre outras.

\section{ASPECTOS ÉTICOS E LEGAIS DA AUDITORIA EM ENFERMAGEM}

A auditoria em Enfermagem está respaldada por uma vasta legislação, que abrange também as suas diversas áreas de atuação, subsidiando os diversos órgãos, governamentais e não-governamentais, para torná-los capazes de apoiar, cada vez mais, as atividades desenvolvidas pela Enfermagem (MOTTA, 2003).

A Lei do Exercício Profissional (Lei 7.498/86), que dispõe sobre a Regulamentação do Exercício da Enfermagem e dá outras providências, e é regulamentada pelo Decreto 94.406/87 (BRASIL, 1987), em seu Artigo 11, inciso I, alínea h (no Decreto

94.406/87, corresponde ao Artigo 8º, inciso I, alínea d) versa que o Enfermeiro exerce todas as atividades de Enfermagem, cabendo-Ihe: privativamente a consultoria, auditoria e emissão de parecer sobre matéria de Enfermagem.

De acordo com o Código de Ética dos Profissionais de Enfermagem (COFEN, 1993), no Capítulo IV - dos deveres, encontram-se dados pertinentes à auditoria em Enfermagem, embora sem maiores especificações, como descrito em seu Artigo 
33: "Proteger o cliente contra danos decorrentes de imperícia ou imprudência por parte de qualquer membro da equipe de saúde." Portanto, a auditoria em Enfermagem é uma ferramenta importante para a proteção do cliente por subsidiar a melhoria da qualidade da assistência. Dessa forma, concordando com Possari (2005, p. 205), "toda informação que não foi registrada é considerada perdida, deixando de oferecer ao paciente as informações corretas a respeito dos cuidados prestados pela equipe de Enfermagem".

\section{MÉTODOS}

Esse tipo de pesquisa pode ser entendido como um estudo de caso onde, após a coleta de dados, é realizada uma análise das relações entre as variáveis para uma posterior determinação dos efeitos resultantes. Auditoria retrospectiva, no qual foi realizada um estudo dos prontuários de pacientes após sua alta, portanto, os dados obtidos não reverterão em benefícios deste paciente diretamente, mas sim para a assistência de maneira global.

O método de coleta de dados e a análise documental foram realizados por meio da análise dos prontuários do paciente.

O estudo foi realizado em um hospital, localizado no Município de Brumado/Ba. È um hospital de grande porte, que dispõe de unidades de internamento, pediatria, centro obstétrico, ambulatório de ortopedia, centro cirúrgico, berçário, pronto socorro, diagnóstico, LACEN - Laboratório Central de Saúde Pública além de realizar procedimentos de alta complexidade.

\section{CRITÉRIOS PARA AVALIAÇÃO E ANÁLISE DOS REGISTROS DE PRONTUÁRIOS}

Os itens avaliados no prontuário foram: admissão de enfermagem; prescrição de enfermagem; evolução de enfermagem; assinatura; carimbo; letra legível; diagnóstico de enfermagem; checagem de enfermagem; checagem da prescrição médica; folha de centro cirúrgico; folha de gasto; anotação de alta hospitalar ou óbito. Os critérios 
utilizados para avaliação foram elaborados em forma de check list, observando à legibilidade, clareza e completude dos mesmos.

Com relação aos itens avaliados, foi utilizado o seguinte critério de pontuação: Ótimo (1 ponto) - 100\%; Bom (0,7 a 0,9 pontos) - 60\% a 99\%; Regular (0,4 a 0,6 pontos) $31 \%$ a $59 \%$; Ruim (0,1 a 0,3 pontos) - menos que $30 \%$; Ausente (0 ponto) não se aplica.

O termo ausente foi utilizado quando o item avaliado não é implantado na unidade: no caso de não haver prescrição de enfermagem não é possível haver a avaliação da checagem da prescrição.

\section{AMOSTRA DO ESTUDO E PERÍODO}

Foram analisados 100 prontuários, período de coleta de dados ocorreu no mês de Março de 2015. Os prontuários foram selecionados pelo SAME - Serviço de Arquivo Médico e Estatístico no mês correspondente.

\section{RESULTADOS}

Foram avaliados no total 100 prontuários de pacientes que foram internados na clínica cirúrgica do Hospital Municipal de Brumado. 


\title{
Admissão de Enfermagem
}

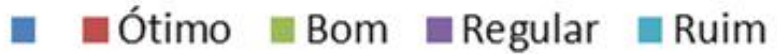

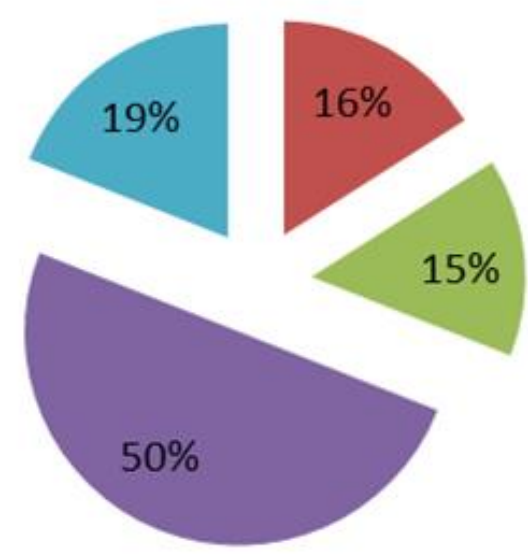

Figura 1 - Gráfico Admissão de Enfermagem. Fonte - Autoria própria. 2017

Dos prontuários avaliados no item admissão de enfermagem como pode ser analisado no gráfico da figura 1 percebeu que os funcionários têm certa dificuldade para relatar a entrada do paciente no hospital.

$16 \%$ estavam completas, admissões bem-feitas; $15 \%$ bom; $50 \%$ regular, faltando admissão de enfermeiros, incompletas, letras ilegíveis e 19\% ruim, sem conteúdo.

A admissão de um paciente no hospital significa a sua chegada à unidade hospitalar. Ao ser admitido, deve ser bem recebido, acomodado e a interação entre o paciente e a equipe de enfermagem. 


\section{Evolução de Enfermagem}

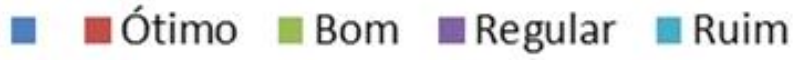

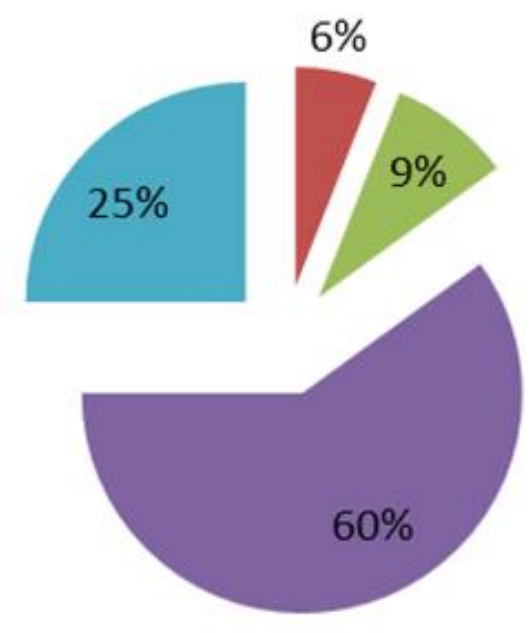

Figura 2 - Gráfico Evolução de Enfermagem. Fonte: Autoria Própria. 2017

$\mathrm{Na}$ figura 2 podemos observar quanto à evolução de enfermagem, sendo elas bastante incompletas, letras ilegíveis e poucas informações necessárias da evolução do paciente, $60 \%$ dos prontuários analisados não possui relato diário dos enfermeiros, possuindo um relato maior da equipe técnica de enfermagem.

Evolução é o registro feito pelo Enfermeiro após a avaliação do estado geral do paciente. Desse registro devem constar os problemas novos identificados, um resumo sucinto dos resultados dos cuidados prescritos e os problemas a serem abordados nas 24 horas subsequentes (COREN, 2000). 


\section{Letra Legível}

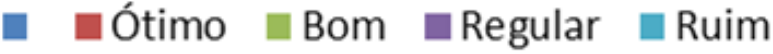

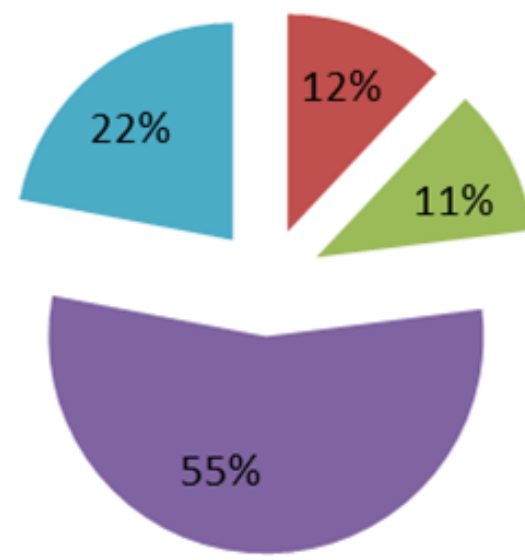

Figura 3 - Gráfico Letra Legível. Fonte: Autoria própria. 2017

Nos prontuários analisados, em relação à letra legível foram encontradas dificuldades para entendimento das anotações de enfermagem, 55\%.

Segundo o Conselho Regional de Medicina do Paraná:

"É sob o aspecto processual/legal que verificamos a importância deste documento no contexto da defesa do profissional. Quer seja sob o âmbito judicial, administrativo, ou ainda ético, o prontuário médico passa a servir ao elevado propósito de defesa de todos os que compõem a equipe assistencial, bem como da instituição de saúde envolvida. Assim, a utilidade do prontuário vai muito além de manter registros sobre a evolução do paciente, pois, na medida em que é considerado um documento legal sob o qual ao mesmo tempo se registra e se respalda as condutas médicas, torna-se talvez o principal meio de prova da atividade médica, cujas informações ali apostadas gozam de presunção legal de veracidade na apuração dos fatos desencadeantes dos processos, no qual é necessária a legibilidade das anotações." 


\section{Checagem médica}

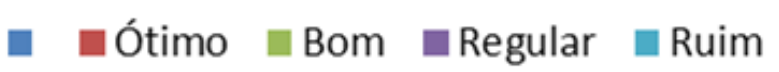

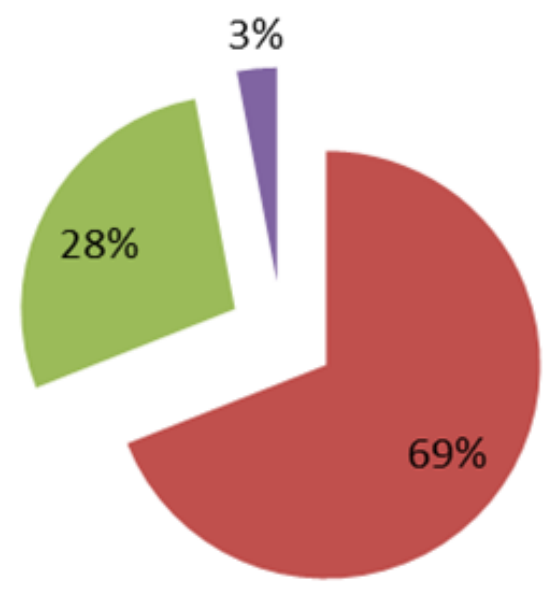

Figura 4 - Gráfico Checagem Médica. Fonte: Autoria própria. 2017

A checagem médica pôde ser observada ótima em $69 \%$ dos prontuários, foi conferido que a sua anotação na folha de evolução também tem sido relatada, porém de forma breve e sucinta, no qual não foram identificadas a via que foi administrada e quantidade. Nos prontuários do HMPMN não possui prescrição de enfermagem, e decorrente disso não possui diagnóstico e checagem de enfermagem.

As assinaturas foram encontradas em $100 \%$ dos prontuários, e os carimbos em $54,2 \%$, onde se encontra a área profissional e o número do seu conselho.

As folhas de gasto observadas estão presentes em todos os prontuários analisados, e devidamente preenchidos.

Os relatórios de alta analisados foram: $11 \%$ ótimo, 32\% bom, $48 \%$ regular, $7 \%$ ruim, e foram observados 2 prontuários sem relatório de alta. 


\section{CONCLUSÃO}

O principal objetivo do prontuário é facilitar a assistência ao paciente, constituindo-se em um meio de comunicação entre os diferentes profissionais da saúde e em um recurso indispensável para assegurar a continuidade do atendimento. Seus registros são cada vez mais, documentos essenciais para a elucidação de questões jurídicas e éticas cada vez mais frequentes, envolvendo pacientes, serviços de saúde e seus profissionais.

Por todos esses motivos, o prontuário não deve ser visto como um conjunto de formulários a serem preenchidos de rotina, mas sim como um depositário de importantes informações que merecem todo o empenho no sentido de se garantir sua qualidade, integridade e confiabilidade. Consideram-se como componentes do prontuário tanto as informações armazenadas em papel como em meio digital, magnético ou qualquer outra forma de registro de dados. A padronização dos registros de enfermagem é necessária, visto que existem falhas no que se refere a adequações gramaticais da linguagem formal, brevidade, legibilidade, identificação e terminologia técnica.

A auditoria é fundamental para detectar problemas apresentados em prontuários, pois possibilita por meio dos relatórios de avaliação a orientação para a equipe e a instituição, em forma de educação continuada, quanto ao registro apropriado das áreas profissionais e o respaldo ético e leal.

Conforme consta na resolução 266 de 05 de outubro de 2001, do Conselho Federal de Enfermagem (COFEN), este profissional, enquanto auditor no exercício de suas atividades deve organizar, dirigir, planejar, coordenar e avaliar, prestar consultoria, auditoria e emissão de parecer sobre os serviços de enfermagem; devendo ainda ter uma visão holística, como qualidade de gestão, qualidade de assistência e quântico econômico - financeira, visando sempre o bem estar do ser humano. 


\section{REFERÊNCIA}

CALEMAN, G.; MOREIRA, M. L.; SANCHEZ, M. C. Auditoria, controle e programação de serviços de saúde. São Paulo: Petrópolis, 1998.

COFEN, http://www.cofen.gov.br/resoluo-cofen-2402000-revogada-pela-resoluocofen-3112007_4280.html, Acessado em 01/08/17, às 13:00.

CONSELHO FEDERAL DE ENFERMAGEM. Resolução COFEN-266/2001. Aprova atividades de Enfermeiro Auditor. Rio de Janeiro (Brasil): COFEN; 2001.

CRM - SP, https://www.cremesp.org.br, Acessado em 01/08/17, às 10:20.

ITO et al. Manual de anotação de enfermagem. São Paulo, SP. 1 ed. Atheneu, 2005, p. $41-42$.

KURCGANT, P. Auditoria em enfermagem. Revista Brasileira de Enfermagem, 1976.

MAUTZ, R. K. Princípios de auditoria. 4. Ed. São Paulo: Atlas, 1995.

MOTTA, A. L. C. Auditoria de Enfermagem nos hospitais e operadoras de planos de saúde. São Paulo: látria, 2003.

PEROVANO, D. G.; Manual de Metodologia Cientifica. Ed. Juruá, 2014

POSSARI, J. F. Prontuário do paciente e os registros de enfermagem. São Paulo: látria, 2005.

Resolução no 160, de 12 de maio de 1993. Aprova o Código de Ética do Profissional de Enfermagem. Rio de Janeiro: COFEN, 1993.

Resolução no 266, de 05 de outubro de 2001. Aprova as atividades do Enfermeiro Auditor. Rio de Janeiro: COFEN, 2001. 
SANTOS S.R.; PAULA A.L.J.; LIMA J.P. O enfermeiro e sua percepção sobre o sistema manual de registro no prontuário. Revista Latinoam Enfermagem 2003 janeiro - fevereiro; 11(1): 80 - 7 . P. 81 . Disponível em http://www.scielo.br/pdf/rlae/v11n1/16563.pdf>. Acessado em 01/08/17, às 14:00 